\title{
Urinary iodine excretion correlates with milk iodine content in seven British towns
}

\author{
M NELSON, ${ }^{1 *}$ D I W PHILLIPS, ${ }^{1}$ J A MORRIS, ${ }^{1}$ AND T J WOOD, ${ }^{2}$ \\ From the MRC Environmental Epidemiology Unit, ${ }^{1}$ University of Southampton, Southampton General Hospital, \\ Southampton SO9 $4 X Y$ and AFRC Institute of Food Research (Reading Laboratory), ${ }^{2}$ Shinfield, Berkshire;
}

SUMMARY In February and May 1986, weekly samples of whole pasteurised milk were collected from the 24 dairies supplying seven British towns. A random sample of 96 women aged 25-64 was drawn from general practitioners' lists in each town, and catch specimens of early morning urine were collected by post from 194 subjects in February and from 186 subjects in May. Median milk iodine concentration was significantly greater in February $(235 \mu \mathrm{g} / 1)$ than in May $(119 \mu \mathrm{g} / 1)$. The median urine iodine concentration (expressed per $\mathrm{g}$ of creatinine) was also greater in February $(106 \mu \mathrm{g} / \mathrm{g}$ ) than in May $(78 \mu \mathrm{g} / \mathrm{g})$. There was a strong and statistically significant correlation between milk and urine iodine concentrations in the seven towns in February (Spearman's $r=0.79, p=0.04$ ). Within the towns, the change in milk iodine levels between February and May was positively associated with the change in the iodine:creatinine ratio over the same period. There is concern that an excess of dietary iodine may be harmful to some individuals. Should it prove desirable to reduce iodine intakes at the community level, the present results suggest that this could be achieved by a reduction in milk iodine levels, which can be readily brought about by adjusting the levels of iodine in cattle feed.

The major dietary sources of iodine in Britain are milk and dairy products, fish, meat, and cereal foods. ${ }^{1}$ Milk is especially important, contributing as much as half of the adult iodine intake in winter, ${ }^{12}$ although it may vary in its iodine content up to twofold geographically and up to fivefold seasonally. ${ }^{34}$ In the light of a possible seasonal association between milk iodine levels and thyrotoxicosis incidence, ${ }^{3}$ it is important to know to what extent milk iodine influences iodine status in the population. Iodine status has been assessed in epidemiological studies by measuring urinary iodine excretion. ${ }^{5}$ We have investigated the correlation between urinary iodine excretion and milk iodine content in seven British towns to see if milk iodine is a major determinant of iodine status in these communities. Also, our results give a measure of urinary iodine excretion in a random sample of British women for the first time in over 20 years.

\section{Methods}

From June 1984 through May 1985, $20 \mathrm{ml}$ of whole pasteurised milk were collected weekly from each of 24

* Present address: Department of Food and Nutritional Sciences, King's College London, Campden Hill Road, London W8 7AH dairies supplying seven British towns: Barrow-inFurness, Chester, Hastings, Middlesbrough, Plymouth, Preston, and Southampton. The towns were those included in a parallel study of milk iodine and thyrotoxicosis. ${ }^{3}$ Representative monthly milk samples for each town were obtained by combining the samples from the different dairies in proportion to their share of the overall milk sales in the towns.

In each town, an age-stratified random sample of 96 women aged 25-64 was drawn from the practice lists of three general practitioners selected to encompass the geographical spread and range of socioeconomic conditions in the town. In late February, approximately half the subjects in each town (total $\mathrm{n}=322$ ) received a letter from their general practitioner and a small parcel holding a $30 \mathrm{ml}$ Sterilin plastic screw-cap sample tube containing $1 \mathrm{~g}$ boric acid, a collecting tray, and instructions to collect a $20 \mathrm{ml}$ catch specimen of early morning urine and return it to the surgery. In May, letters and parcels were posted to the remaining subjects $(n=298)$. The net response rate was $62 \%$ in February (between 54 and $70 \%$ in the individual towns) and $67 \%(54-77 \%)$ in May. Because (a) our aim was to collect the urine samples within intervals that corresponded to periods 
of relatively stable milk iodine levels (3-4 weeks), and (b) the delay between the initial posting and the return of the samples from the general practitioners was of the order of two to three weeks, there was not sufficient time to arrange second postings to nonresponders.

Iodine concentration in milk and urine was determined using a modification of the dry-ashing method of Moxon and Dixon. ${ }^{6}$ The 84 monthly milk samples were analysed individually. Average urinary iodine excretion in each town was estimated as follows:

The February urine samples were analysed individually for creatinine using a two point modification of the Jaffé reaction on the LKB reaction rate analyser. All the samples were ranked according to creatinine concentration and divided into three groups: high creatinine (above the 3rd quartile); medium (between the 1st and 3rd quartiles); and low (below the 1st quartile). In each town, aliquots of the individual samples were combined according to their creatinine values (low, medium or high) to give three pooled samples, which were then analysed for creatinine and iodine concentration. Urinary iodine excretion in each town was expressed as the weighted average of the iodine:creatinine (I:Cr) ratios of each of the three pooled samples. The May samples were analysed in the same way.

The validity of this technique for estimating group iodine excretion was tested by conducting iodine and creatinine analyses on all individual urine samples in one town (Hastings) for one month (February) and comparing the mean of the individual $\mathrm{I}: \mathrm{Cr}$ ratios with the value calculated from the pooled samples as above. The two methods of calculation gave $\mathrm{I}: \mathrm{Cr}$ ratios differing by less than $2.6 \mu \mathrm{g} / \mathrm{g}$, well within the limits of analytical error of the technique for iodine estimation.

\section{Results}

The table shows milk iodine concentration $(\mu \mathrm{g} / 1)$ in the seven towns over 12 months and in February and May. Annual averages ranged from $130 \mu \mathrm{g} / 1$ in Barrow to $200 \mu \mathrm{g} / 1$ in Plymouth. Median milk iodine concentration was significantly higher in February $(235 \mu \mathrm{g} / 1)$ than in May $(119 \mu \mathrm{g} / 1)(\mathrm{p}=0.02$, Wilcoxon rank sum test). Differences in milk iodine concentration between towns ranged from 4 to $131 \mu \mathrm{g} / 1$ in February and from 6 to $62 \mu \mathrm{g} / 1$ in May, whereas differences between values in February and May within towns ranged from 7 to $185 \mu \mathrm{g} / 1$. Seasonal differences within towns were thus greater than the geographical differences between towns.

The I:Cr ratios for the seven towns in February and May are also shown in the table. Values ranged from 90 to $126 \mu \mathrm{g} / \mathrm{g}$ in February and from 66 to $97 \mu \mathrm{g} / \mathrm{g}$ in May. The median I:Cr ratio in February $(106 \mu \mathrm{g} / \mathrm{g})$ was significantly greater than in May $(78 \mu \mathrm{g} / \mathrm{g})$ $(p=0.02$, Wilcoxon rank sum test).

The geographical association between milk iodine concentration and the $\mathrm{I}: \mathrm{Cr}$ ratio in the seven towns in February and May is shown in figure 1. In February, there was a strong and statistically significant positive correlation between milk iodine levels and urinary iodine excretion in the towns (Spearman's $r=0.79$, $\mathrm{p}=0.04)$. In May, the relation was less strong (Spearman's $r=0.61$ ) and did not reach statistical significance $(p=0 \cdot 15)$.

Figure 2 shows that, within the towns, the change in milk iodine levels between February and May was positively correlated with the change in the average I:Cr ratio over the same period (Spearman's $r=0.61$ ),

Average annual, February, and May milk iodine concentrations ( $\mu g / 1)$ in seven English towns; and average urinary iodine:creatinine ratio ( $\mu \mathrm{g} / \mathrm{g}$ ) in February and May in pooled casual specimens from women aged 25-64 (see text for method of calculation).

\begin{tabular}{|c|c|c|c|c|c|}
\hline \multirow[b]{2}{*}{ Town } & \multicolumn{3}{|c|}{ Milk iodine concentration $(\mu g / 1)$} & \multicolumn{2}{|c|}{$I: C r$ ratio $(\mu g / g)$} \\
\hline & Annual & February & May & February & May \\
\hline Barrow & 130 & 178 & 126 & 90 & 67 \\
\hline Chester & 132 & 158 & 93 & 102 & 76 \\
\hline Hastings & 162 & 289 & 104 & 115 & 78 \\
\hline Middlesbrough & 142 & 235 & 99 & 106 & 66 \\
\hline Plymouth & 200 & 282 & 130 & 124 & 88 \\
\hline Preston & 154 & 162 & 155 & 102 & 97 \\
\hline Southampton & 166 & 257 & 119 & 126 & 78 \\
\hline \multicolumn{6}{|l|}{ All towns } \\
\hline Median & 154 & 235 & 119 & 106 & 78 \\
\hline
\end{tabular}




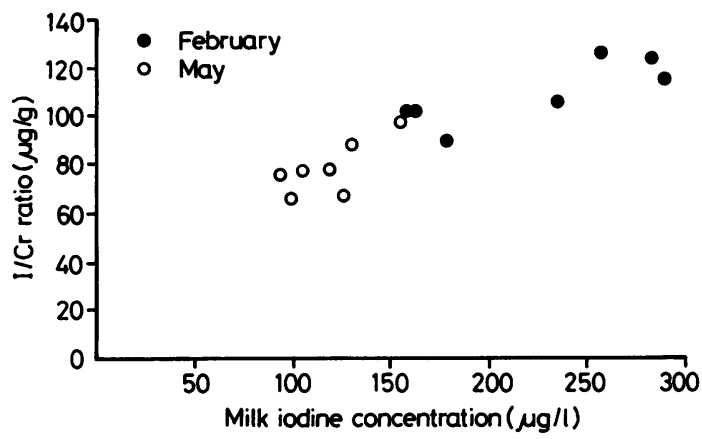

Fig 1 Urinary iodine excretion (iodine:creatinine ratio, $\mu \mathrm{g} / \mathrm{g}$ ) versus milk iodine concentration $(\mu \mathrm{g} / 1)$ in seven English towns in February (O) and May (O). Spearman's rank correlation coefficient: February: $r=0.79, p=0.04 ;$ May: $r=0 \cdot 61, p=0 \cdot 15$.

although this fell short of formal statistical significance $(p=0 \cdot 15)$. The figure shows that for every $100 \mu \mathrm{g} / 1$ increase in milk iodine concentration there was an average corresponding increase of $18 \mu \mathrm{g} / \mathrm{g}$ in the $\mathrm{I}: \mathrm{Cr}$ ratio.

\section{Discussion}

This study has shown that the marked seasonal and geographical variations in urinary iodine excretion in seven British towns correlate strongly with the iodine content of milk.

Iodine in milk is derived from cattle feed enriched with iodine ${ }^{7}$ and, to a lesser extent, iodophors used for teat disinfection and sterilisation of milk equipment. ${ }^{8}$ The raised milk iodine concentration in February reflects higher feed levels in winter and confirms previous findings. ${ }^{24}$ The seasonal differences in milk

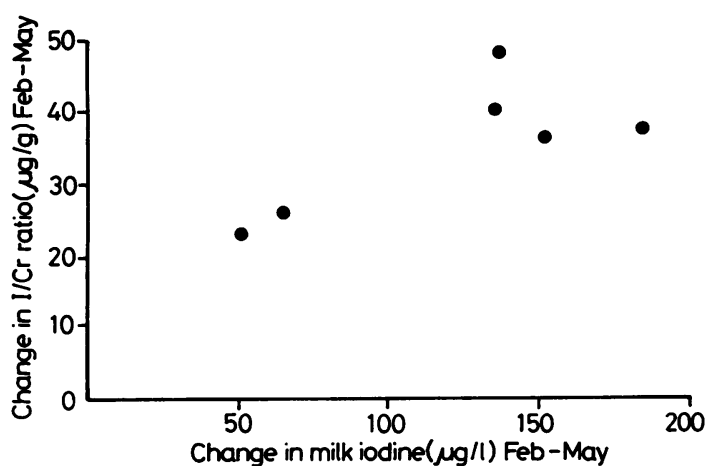

Fig 2 Change in urinary iodine excretion (iodine:creatinine ratio, $\mu \mathrm{g} / \mathrm{g}$ ) between February and May versus change in milk iodine concentration ( $\mu \mathrm{g} / 1)$ over the same period in seven English towns. Spearman's rank correlation coefficient: $r=0 \cdot 61, p=0 \cdot 15$. iodine content were more pronounced than the regional differences.

There were no significant differences in the distribution of urine creatinine concentration in the low, medium, and high groups between towns in either February $\left(\chi^{2}=3.04, p>0.975\right)$ or May $\left(\chi^{2}=14.06\right.$, $p=0 \cdot 31)$. Given the method of sampling and the similarity of response in each town, it is unlikely that there were major differences in the average level of creatinine excretion from one town to another. Moreover, there is no reason to believe that there were systematic differences in the levels of creatinine or iodine excretion between responders and nonresponders. If it is assumed that average daily creatinine excretion in these women was about $1 \mathrm{~g}$ $(8.8 \mathrm{mmol})$ a day, ${ }^{9}$ then the results for the urinary $\mathrm{I}: \mathrm{Cr}$ ratio suggest that daily iodine excretion was of the order of 63-101 $\mu \mathrm{g}$ in summer and $90-126 \mu \mathrm{g}$ in winter. Theses values are similar to estimates of iodine excretion in 1963-42 despite a doubling of milk iodine levels in the 20 year interval. They also agree with the median estimate of daily iodine excretion in Preston $(70 \mu \mathrm{g})$ and Southampton $(76 \mu \mathrm{g})$ in August 1983, based on 24-hour urine collections. ${ }^{10}$ The available evidence thus suggests that while milk iodine concentration has increased in the last 20 years, there has been no apparent change in the levels of urinary iodine excretion. This may be due to changes in diet over this period (eg, the decline in fish consumption from $5.94 \mathrm{oz}$ per person per week in 1964 to $4.89 \mathrm{oz}$ per person per week in $1984^{11}$ ); to differences in analytical techniques used in the different studies of iodine excretion; or because the methods for estimating iodine excretion differed in the two studies (individual $v$ pooled samples). These results do not alter the conclusion that the proportion of dietary iodine from milk has increased substantially over the last 20 years. Nor do they undermine the strength of the correlation between urinary iodine excretion and milk iodine concentration observed in the present study. Thus, in spite of the modest response rates (range $54-77 \%$ ), the $\mathrm{I}: \mathrm{Cr}$ ratio may be of value in estimating the relative iodine excretion between towns. This method for collecting urine "by post" may have application in other epidemiological surveys, particularly where more than one posting is possible and response rates can be improved.

Urinary iodine excretion has been shown in metabolic balance studies to be directly related to levels of iodine intake and not to individual differences in iodine absorption or faecal losses, ${ }^{212}$ The community differences in the average $\mathrm{I}: \mathrm{Cr}$ ratio observed in the present study are therefore likely to relate primarily to differences in iodine intake. As milk consumption shows little regional variation in England, ${ }^{11}$ it can be concluded from fig 1 that 
much of the difference in urinary iodine excretion between towns in February is likely to be due to the difference in milk iodine levels. This is consistent with the finding that $39-46 \%$ of dietary iodine in winter is derived from milk alone. ${ }^{1}$ In May, when milk contributes only $9-15 \%$ of dietary iodine, other sources such as meat, eggs, and fish presumably account for a greater proportion of the geographical variation in urinary iodine excretion.

The seasonal differences in iodine excretion are similarly accounted for by the February-May differences in milk iodine levels. Average milk intake in Britain is 3.47 pints per person per week, ${ }^{11}$ equivalent to $281 \mathrm{~g}$ a day. A change in milk iodine of $100 \mu \mathrm{g} / 1$ would thus yield an extra $28 \mu \mathrm{g} \mathrm{I} /$ day. Figure 2 suggests that approximately 18 out of the $28 \mu \mathrm{g}$ would be lost in the urine. This represents an absorption rate of $64 \%$, similar to previously reported values. $^{2}$

The minimum level of iodine intake required to prevent goitre is well established at $75 \mu \mathrm{g} /$ day in adults. ${ }^{13}$ There is concern, however, that an excess of iodine may be harmful to some individuals: the peak in the onset of thyrotoxicosis correlates with the winter peak in milk iodine concentration. ${ }^{3}$ Should it prove desirable to alter the average level of iodine intake in the community as a whole, the observation that a constant proportion of iodine from cattle feed is excreted in the milk, ${ }^{2,14}$ coupled with the findings of the present study, suggests that such an alteration could be readily effected by changing the iodine level in feed.

We extend our thanks to S P Cox for help in piloting the postal method for the collection of urine, Dr G Morreale de Escobar for analysis of iodine in validating the pooled sample method for estimating iodine excretion in groups, to the general practitioners in the seven towns for allowing access to their patient lists for sample selection, and to the women without whose cooperation the study would not have been possible.

\section{References}

${ }^{1}$ Nelson M, Phillips DIW. Seasonal variations in dietary iodine intake and thyrotoxicosis. Hum Nutr: Appl Nutr 1985; 39A: 213-6.

${ }^{2}$ Broadhead GD, Pearson IB, Wilson GM. Seasonal changes in iodine metabolism. Br Med J 1965; 1: 343-8.

${ }^{3}$ Phillips DIW, Nelson M, Barker DJP, Morris JA, Wood TJ. Iodine in milk and the incidence of thyrotoxicosis in England. Clin Endocrinol 1988; 28: 61-6.

${ }^{4}$ Wenlock RW, Buss DH, Moxon RE, Bunton NG. Trace nutrients 4: Iodine in British food. Br J Nutr 1982; 47: 381-90.

${ }^{5}$ Konig MP, Mordasini C, Kohler H, Lauber K. Diagnostic value of the measurement of iodine in blood and urine. in: Thyroid disorders associated with iodine deficiency and excess, ed Hall R, Kobberling J. New York: Raven Press, 1984.

${ }^{6}$ Moxon RED, Dixon EJ. Semi-automatic method for the determination of total iodine in food. Analyst 1980; 105: $344-52$.

${ }^{7}$ Underwood EJ. Trace elements in human and animal nutrition. London: Academic Press, 1977: 271-91.

${ }^{8}$ Dodd FH, Wan Embong WH, Kingwill RG, Lewis G, Salt FJ. The effect of iodophor teat disinfection on the iodine content of milk. 20th International Dairy Congress, 166. Paris: Congrilait.

${ }^{9}$ West ES, Todd WR, Mason HS, van Bruggen JT. Textbook of biochemistry, 4th ed. London: MacMillan, 1966.

${ }^{10}$ Nelson M, Quayle A, Phillips DIW. Iodine intake and excretion in two British towns: aspects of questionnaire validation. Hum Nutr: Appl Nutr 1987; 41A: 187-92.

${ }^{11}$ Ministry of Agriculture, Fisheries, and Food. Household food consumption and expenditure: 1964, 1984. London: HMSO, 1966, 1986.

12 Vought RL, London WT, Lutwak L, Dublin TD. Reliability of estimates of serum inorganic iodine and daily fecal and urinary iodine excretion from single casual specimens. J Clin Endocrinol 1963; 23: 1218-28.

${ }^{13}$ Food and Agriculture Organization. Handbook on human nutritional requirements. FAO Nutritional Studies No. 28. Rome: FAO. 1974.

${ }^{14}$ Alderman G, Stranks MH. The iodine content of bulk herd milk in summer in relation to estimated dietary intake of cows. J Sci Fd Agric 1967; 18: 151-3. 